\title{
SIGAMOS DISCUTIENDO SOBRE EL PATERNALISMO
}

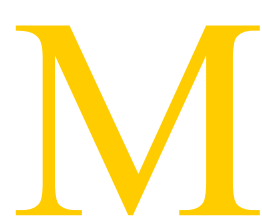

anuel Atienza ha formulado una serie de observaciones críticas a mi trabajo sobre el paternalismo jurídico a las que quiero referirme brevemente.

Pienso que algunas de las observaciones resultan del intento emprendido por Atienza en la sección 2 de su estudio, en el sentido de buscar una definición de paternalismo que sea común a las propuestas de Victoria Camps, Paulette Dieterlen y a la mía propia. Este intento tiene sin duda sus ventajas, pues permite unificar las críticas. El inconveniente es que, en aras de la unidad, pueden perderse algunos matices que luego resultan ser significativos. Pienso que esto es lo que ha sucedido, al menos por lo que respecta a la definición del paternalismo.

La condición $a$ ) de la definición reconstruida hace referencia a la obtención de «un bien». En mi definición, en cambio, se habla de evitar un «daño». Tal como lo señalara en mi trabajo, esta distinción es importante justamente para distinguir el paternalismo jurídico de «otras dos formas de intervención coactiva relacionadas, aunque no idénticas, con el paternalismo jurídico propiamente dicho: cuando el Estado interviene con el propósito de asegurar un beneficio... y el perfeccionismo... En estos dos tipos de intervenciones la idea de aumentar o promover el bien es la decisiva...» Es decir, excluyo expresamente de mi definición de paternalismo jurídico la idea de la obtención del bien, que Atienza incluye en su condición a). Si hubiese seguido la vía sugerida por Atienza, pienso que entonces sí habría caído en la «ambivalencia» o «indefinición» que me reprocha en 2. 1. La no inclusión de la idea de bien no obedece, desde luego, a preferencias más o menos arbitrarias o al propósito de contar con un recurso que me permita adoptar una posición valorativamente neutra frente al paternalismo, sino al deseo de utilizar una definición generalmente aceptada.

Por lo que respecta a la condición b) de la definición reconstruida no tengo inconveniente en aceptar la propuesta de Atienza 
siempre que se suprima la frase entre paréntesis, ya que en ella se hace referencia a «beneficiarios», referencia que parece estar vinculada con la idea de la obtención de un bien, que no comparto.

El hecho de que la norma que incluye una medida paternalista sea una prohibición, un mandato o una permisión creo que es irrelevante, ya que lo que importa es que la medida se imponga en contra de la voluntad del destinatario de la misma: alguien, por ejemplo, podría oponerse a que el Estado o el médico estén autorizados a no informar a sus ciudadanos o pacientes. En este sentido, tiene razón Atienza cuando señala que mi referencia a prohibiciones y mandatos puede restringir indebidamente el concepto de paternalismo jurídico.

En el centro de mi propuesta de argumentos justificatorios del paternalismo jurídico se encuentra la idea del incompetente básico. En la definición del mismo no creo haber introducido ningún elemento de evaluación ética: los cinco casos de incompetencia básica que menciono hacen referencia a datos empíricos. El componente ético del argumento de justificación (la premisa ética, que debe ser distinguida de la premisa empírica, es decir, de la verificación de la incompetencia básica) hace referencia a la necesidad de superar el déficit de igualdad de los incompetentes básicos y presupone, por cierto, la aceptación de que la igualdad y la autonomía de las personas son valores dignos de ser respetados. Como los argumentos que suelen aducirse en contra del paternalismo se basan precisamente en la supuesta violación de ambos valores, me interesaba demostrar que -sin necesidad de invocar unilateralmente ninguna teoría objetivista de la moral- podían rebatirse estas objeciones tomando en consideración sus propios puntos de partida: si el paternalismo jurídico supera o contribuye a superar los déficits de igualdad y autonomía que padecen los incompetentes básicos, entonces quienes defienden los valores de la igualdad y la autonomía tendrán que admitir que es éticamente justificable.

En la sección 3. 2. de su trabajo, Atienza sostiene que, de acuerdo con mi posición, el paternalismo jurídico estaría justificado «si y sólo si se aplica a un incompetente básico para procurarle un bien primario» y que he «descuidado un tanto la cuestión de con arreglo a qué procedimiento deben (los competentes básicos) definir cuáles sean esos bienes y quiénes sean esos incompetentes». La objeción de Atienza introduce nuevamente el concepto de «bien», que he procurado evitar cuidadosamente en mi definición de paternalismo. Por lo que respecta al «procedimiento» para la determinación de los incompetentes básicos, 
creo haber indicado con suficiente claridad cuáles son los casos que pienso pueden ser incluidos en esta categoría; para saber cuándo ellos se dan, basta con recurrir a los procedimientos empíricos usuales que nos permiten determinar situaciones de compulsión, de ignorancia de los elementos relevantes de un estado de cosas o de emoción violenta, por ejemplo.

Atienza insiste en que la aceptación de la condición c) que formula en 3. es fundamental para la definición del paternalismo justificado. No hay duda que quien rechaza la medida paternalista lo hace por encontrarse en la situación de un incompetente básico. La condición c) de Atienza está contenida en mi frase que dice «quien rechaza la medida paternalista lo hace porque en ese momento no está en condiciones de comprender el alcance de la misma». Como de aquí infiero la utilidad del concepto de «incompetente básico» no creo que valga en mi caso la observación de Atienza en el sentido de no haber otorgado al requisito $c$ ) toda la importancia que merece, como afirma en 3. 3 .

Atienza sostiene que no he tomado suficientemente en cuenta el concepto de consenso racional. Al respecto, creo que basta recordar que en mi trabajo los casos c) y e) de «incompetencia básica» se refieren directamente a situaciones en las que lo que se pone en duda es la racionalidad del agente, algo que se da por admitido en los casos que excluyo del paternalismo justificado, precisamente porque presupongo la racionalidad del destinatario de la posible medida paternalista: son los casos del suicida, del amante del riesgo y del héroe.

Vistas así las cosas, pienso que, como el mismo Atienza lo dice en su sección 4., en el fondo nuestras posiciones no difieren básicamente. Sin embargo, hay dos puntos en los que sí existen diferencias significativas. El primero se refiere a la conveniencia de introducir en la definición el concepto de «bien». Mi opinión es que esto puede ser fuente de las mismas deficiencias que Atienza desea superar. En efecto, ello nos impide distinguir los casos de paternalismo jurídico, que pueden ser justificables, de los del perfeccionismo moral, que me inclino a pensar nunca lo son. Por ello no veo la conveniencia de formular un concepto de paternalismo jurídico demasiado amplio, como sugiere Atienza.

Y por supuesto que estamos en desacuerdo por lo que respecta a la irracionalidad del fumador. Si el lector se ha dado cuenta que soy un fumador empedernido (como afirma, con razón, Atienza) también habrá percibido que Atienza es un despiadado adversario de los fumadores, a quienes no vacilaría en colocarlos en la clase de los incompetentes básicos.

Atienza argumentaría posiblemente que la racionalidad de 
las personas se mide por la persecución coherente de sus intereses y que si la persona reflexiona seriamente acerca de los peligros del fumar tendría que no hacerlo, de la misma manera que quien reflexiona sobre los peligros que encierra no usar el cinturón de seguridad en los automóviles tiene que concluir que es conveniente usarlo. Y como yo he aceptado que el caso de quien se niega a usar el cinturón debe ser considerado como un ejemplo de irracionalidad, también debería aceptar -concluiría Atienza- que el fumador es un ser que adopta decisiones irracionales. Sin embargo hay una diferencia: la incoherencia en el caso del automovilista resulta del hecho de que se supone que él desea $Y$ (cuidar su vida), sabe que $X$ (el cinturón) es condición necesaria para $Y$, no tiene nada que objetar en contra de $X$ y se niega a usarlo. En el caso del fumador, en cambio, si bien es cierto que puede desear $Y$ y sabe que $X$ es condición necesaria para $Y$, no está dispuesto a recurrir a $X$ (no fumar), pues, desde el punto de vista de su elección subjetiva, valora $X$ menos que el displacer que le proporcionaría $X$. Aquí puede ser instructiva una reflexión de David Gauthier (Morals by agreement, 1986, 34 y sigs.): «Aquellos que creen que el fumar es nocivo para la salud si son racionales tienen que elegir no fumar, a menos que su interés en la salud sea superado por alguna otra preferencia más fuerte e igualmente reflexionada.» En este sentido la equiparación sugerida del fumador empedernido con el automovilista incoherente no es correcta y abre la peligrosa vía de aplicar prohibiciones paternalistas a los casos del suicida, del héroe y de quien prefiere asumir ciertos riesgos en aras de lo que él mismo entiende como satisfacción de sus preferencias. En la medida en que no exista conflicto entre preferencias y actitudes, me parece difícil que pueda hablarse de incoherencia. Justamente el rechazo de un perfeccionismo moral, que pretende sustituir las preferencias subjetivas de la gente por las supuestamente objetivas de un dictador moral, exige excluir del paternalismo justificable los casos del fumador, del suicida, del héroe y del amante del riesgo. Su inclusión requeriría un concepto de racionalidad (que creo Atienza no aceptaría) que permitiera calificar de irracionales a las preferencias subjetivas de la gente, también cuando ellas resultan de una evaluación ponderada de las alternativas disponibles. Quien, como el Fausto, prefiere canjear su posibilidad de felicidad eterna en el más allá por el placer terreno, puede ser calificado, cuando más, de hedonista fugaz, pero no de irracional. El caso del automovilista que no usa cinturón de seguridad y arriesga su vida cuando en realidad no es eso lo que prefiere es por ello distinto del automovilista Alain Prost, que prefiere correr 
el riesgo de la muerte en cada carrera. En el primer caso hay incoherencia entre preferencia y actitud; en el segundo, no.

El caso del fumador es trivial, como Atienza mismo reconoce, pero también «interesante». En efecto, demuestra que la inclusión del concepto de «bien» en la condición a) de la definición de Atienza no es tan inofensiva como a primera vista parece. El afán de asegurar un «bien» o de «beneficiar» a los destinatarios de las medidas paternalistas puede conducirnos a la aceptación de bienes absolutos u «objetivos» que nos lleven a la prohibición del suicidio y de todas las acciones que pongan en peligro los bienes «objetivos» de la vida o la salud. La conclusión de Atienza con respecto al fumador no parece ser muy distinta de la de William Blackstone con respecto a los suicidas: «el mero acto del suicidio es prueba evidente de locura». Como sé que Atienza no sustenta esta posición, pienso que tendría que revisar su juicio acerca de los fumadores.

Estas últimas consideraciones sé que incitarán el ánimo crítico de Atienza y, como lo conozco, sé también que no se dará por vencido y que buscará nuevos argumentos y contraejemplos. Por ello, nuestra discusión no concluye aquí. Si el lector encuentra nuevas razones para asumir una u otra posición, habremos logrado el fin que nos habíamos propuesto Manuel Atienza y yo al seguir discutiendo sobre el paternalismo y su posible justificación ética. 